\title{
Recovery-Oriented Risk Assessment and Shared Decision Making. Mapping the Process of Recovery in Mental Health Care
}

\author{
Jan Sitvast* \\ Senior lecturer, Europe \\ *Corresponding author: Jan Sitvast, Senior lecturer, Europe
}

Submission: 漹 July 18, 2018; Published: 眥 November 26, 2018

\section{Shared Decision Making and Recovery}

Shared Decision Making has become paradigmatic in health care. By shared decision-making is meant that both the process and outcome of decisions about treatment options are shared between patient and provider. In mental health care it has very much been associated with the patient's recovery process. In the over-arching mental health policy framework that the UK government uses, recovery has been defined as: "A deeply personal, unique process of changing one's attitudes, values, feelings, goals, skills and/or roles. It is a way of living a satisfying, hopeful and contributing life, even with limitations caused by the illness. Recovery involves the development of new meaning and purpose in one's life." It is the task of the professional to facilitate this process by empowering the patient: enlarging the scope of his autonomy and self-direction, giving a person as much regime over his own life as possible and sharing the responsibility for decisions about treatment options. However, a dilemma looms up here if and when the patient and the professional have a different opinion on decisions that, according to the professional, may have the risk to land the patient in trouble: exacerbation of symptoms, increasing social exclusion, etc., but which the patient nevertheless wants and which he defends as his good right as an autonomous person.

\section{Case Report}

Sharon, a young woman of 26 has been secluded for 5 years because of her self-destructive behavior and aggression towards others: self-mutilation, self-strangulation efforts, arsonry and threatening others with a knife. Then she was transferred to another ward where seclusion was no option. Every time that she showed dangerous and self-destructive behavior the nurses considered this as an expression of a deeper felt conflict and they tried to tackle it on this level. In the beginning there was still a lot of strangulation and suicidal acts and of course, nurses first disentangled cords before they engaged in talking with the patient about what her needs were or what tormented her and what could be done about it. This was a way of normalizing relationships within a space that did not rob her from being an agent of her own life. She could go out for instance and visit the nearby shopping center.
In the beginning it happened that the police brought her back when she lay down in the middle of a shop, talking about dying or suicide but these incidents decreased after a while when it dawned upon her that staff would stick to the treatment policy to treat underlying problems. In the course of time a working alliance with her could be forged. The staff and the patient started to recognize early signals of rising tensions and most of the times escalation could be prevented. Her functioning improved, and she felt in better shape, even so that she could take up a volunteer job in a counseling agency for psychiatric treatment.

\section{Risk Monitoring and Safety Planning}

The mental health staff engaged with her in therapeutic or positive risk-taking. Positive risk-taking aims at involving the person taking on new challenges leading to personal growth and development. This is an aspect of recovery-oriented care. When service users are denied this positive risk-taking then recovery is frustrated [1-6]. There is, we can say, a dignity of risks: without risks no challenges. Having said this, we must at the same time realize that prevention of damage caused by compulsory admission when this could have been avoided by monitoring risks and signals of distress is another priority, especially when we know that in several Western countries, the rate of such admissions is tending to rise [7]. We need to pay attention to areas of tension in the treatment where the professional perspective may be at odds with the perspective of the patient, for instance on medication, what must be done in acute crisis situations and how seclusion and restraint can be avoided.

A recent meta-analysis [7] proved that crisis plans that are drafted in collaboration between patient and caretakers can reduce the number of compulsory admissions with $25 \%$. Especially the concrete description of situations that the patient can recognize as his sources of stress and the things he can do to cope with stress, alone or together with family, friends and caretakers in order to prevent compulsory admission, has been shown to be effective, more than anything else. This may be more in the field of functional and clinical recovery, which however cannot be altogether seen 
apart from personal recovery (as outlined in the definition by the UK Department of Health). Monitoring of risks can be considered as one of the challenges of recovery-oriented care. The focus of mental health professionals and the general public is however on so-called dramatic risks: the risk of suicide, self-harm, substance abuse (risk to self) and violence (risk to others).

The dilemma is that these dramatic risks are so much foregrounded that positive risk-taking gets little attention and that there is little evidence of recovery-oriented practice in relation to risk [8]. Risk management and safety plans are still frequently concerned with 'avoiding danger, restrictions, containment, protection and staff control. Besides, risks from others and 'iatrogenic' risks are often overlooked, which is strange while we know that people with mental health problems run into the risk of financial exploitation, sexual vulnerability and social exclusion and victimization in the community much more frequently than the general public [8]. The negative impact of side-effects of psychotropic medication on people's quality of life and physical health (an example of iatrogenic risk) is often not considered as part of a risk assessment, due to the narrow perspective of risk monitoring as crisis intervention with a focus on 'extreme' risks. Looking back on the opening phrases just after the presentation of the case, where we argued not to overlook the prevention of the damage caused by compulsory admission, we must admit that we did exactly the same. To our defence we can answer that many 'incidents' reported in the case invited us to focus on dramatic risks -threatening with suicide for instance- at the cost of risks that are part and parcel of everyday life so to speak as social exclusion and victimization due to the young woman's inappropriate behavior in the shopping centre. How to sail between the cliffs of Scylla and Charybdis and avoid the two evils: ignoring risks on the one hand and dramatizing them on the other hand? The solution may be found in making risk monitoring part of a broader assessment.

\section{Recovery-Oriented Assessment}

As part of a broader assessment recovery-oriented risk monitoring and safety-planning should focus on providing opportunities for service users to experience autonomy and control, building on strengths, resources and capabilities and learn from situations (crises) in order to cope better in future. Assessing these aspects is what a service user may need to go forward with recovery. Respecting the public's right to be guarded from unwanted negative outcomes need not conflict with this agenda, as participation in society is part of the recovery process. The kind of inappropriate behavior that the young woman demonstrated in the case will not help her very much to become a respected member of society, so that is a lesson she had to learn. We must realize that recovery involves the formation of new identity and that the development of new meaning and purpose is part of that process. An assessment of risks and challenges (their counterpart) cannot be separated from how in recovery someone's identity is constituted. We will come back to this issue later.

\section{Recovery Oriented Care: Making Transparent what must be Done}

The aspects that need attention in recovery-oriented care, because they are central in the development of a new identity (or an old identity reconstructed) are also those that should figure on the agenda of shared decision making [9] and therefore need to be taken stock of. We distinguish:

i. Wishes and ambitions

ii. Strengths

iii. Values

iv. Support

v. Risks and challenges

They can be considered parameters in the recovery process, in the sense that we can ask, for instance: how many of your wishes and ambitions are expressed in your recovery narrative; to what degree do you make use of your sources of strengths to build your recovery from?

\section{The Constitution of Identity in Recovery Trajectories}

Therefore, mentioned aspects serve the dialogue between professionals and service users as part of a shared decision-making process. They reflect a dynamic reality that moves beyond the 'closed' narrative of diagnosis and disease scripts that fatefully predict negative outcomes $[10,11]$. Someone's story is much more the vehicle for making meaning of one's experiences and re-positioning of one's social identity when necessary. As Felton \& Stickley [12] put it: "The opportunity for new narratives and interpretations are important in terms of risk, particularly in relation to historical incidents of harm caused by or to an individual. The reinterpretation of events provides scope for people to come to terms and move on in accordance with the principles of recovery. Engaging with people's own interpretations of these also enables professionals to consider the meaning of such events in the context of peoples current circumstances."

The 5 aspects or parameters can be helpful in an ongoing evaluation of the process of recovery and can be considered as a bench job for discussion in a shared decision-making conversation. Safety planning and drafting of crisis plans may be the decision pole of the deliberations as an outcome of the consensus the service user and professional agrees on in their interpretation of how things go. Where there is no consensus and the professional perspective is at odds with the perspective of the patient, for instance on medication and what must be done in acute crisis situations, then it is the professional's first responsibility to discuss the consequences of this disagreement with the service user as far as this implies possible actions aimed at prevention of extreme harm. As we know from other studies service users will then often defer to the advice of the case manager, especially in the case where 
the relation between service user and case manager has been built on trust [13], as was the case with the young woman who learnt to recognize the signals of her emotional disarray. If not so and there is an unacceptable risk for extreme harm, then it can be necessary to take over self-direction from the service user and even apply measures of constraint.

\section{Shared Decision Making as a Moral Praxis}

The shared decision-making process yields good results if it is based on trust and a satisfactory and efficient working alliance between service user, his relatives and other stakeholders and professional caretakers. Therefore, it must connect the reflection on important issues, their expression in recognizable iconic images (that represent these issues) and the sharing. Sharing is much more than merely exchanging views and trying to reach a consensus. It is a moral praxis in which commitment from both parties is crucial. The professional must engage him/herself in the relationship. Shared decision making is not just another intervention. Establishing a relationship between professionals and service users is an essential part of it [13]. We can speak of professional repertoires, fixed sets of activities that professionals are accustomed to carry out and that patients and society expect them to carry out [14]. The professional repertoire of interventions/intervening is one of them (and the dominant repertoire in health care). It has been based on problemidentification/diagnosis, treatment planning and interventions.

An alternative repertoire is that of "presence and presencing" (Baart [15] for the theory on the presence approach). Presence in this context means that professionals do their work in such a way that service users experience the professionals as being there for them [14]. Shared decision making is a rational process with an information aspect, options to choose from and a decisional moment, but it is also a relational process. How to inform the patient, offer options to choose and take the necessary steps to reach at a decision may be seen as professional skills that are part of an intervention. But at the same time, it concerns persons who suffer and who make an appeal on professionals to help them. The process of shared decision making is very much relational and has a moral dimension. The professional must be present in the relationship and committed to alleviate the service user's suffering. Presence is very much about relating as a person to another person, on the basis of authenticity instead of professional distance.

It may conflict with the 'empowerment', as an ideal in health care that dictates professionals to work with patients on a symmetrical basis and consider them as consumers who can well reason what is best for them. This becomes clear from the dilemma that on the one hand the professional wants to prevent extreme harm from risks that the service user is willing to take, and on the other hand his intention to enlarge the scope of the service user's autonomy and self-direction, giving a person as much regie over his own life as possible. From an asymmetrical point of view that recognizes that patients can be needy and not (anyway not always) in control, the monitoring of risks may not always be effective in preventing harm as it is conditional on a certain degree of rational thinking (which may be absent). There are two options the professional can choose from.

$\mathrm{He} /$ she can opt for intervening and protect the service user from serious harm by taking over directional control. Paradoxically, this can be sensed by a service user as true commitment to a his or her well-being, although in some cases he/she would not be ready to admit that. The other option is that the professional exercises self-control and allows the other person to determine the course of events. Following one of the principles of presence the professional can radically adopt "the other person's perspective, reconstruct the logic of the situation as perceived by that person, and take his or her side" [14]. This is ultimately what was done in the case of Sharon. Of-course there was no imminent danger and no risk of extreme harm.

\section{Discussion and Conclusion}

Recovery-oriented risk monitoring and safety-planning should be part of a broader assessment and avoid a focus on dramatic 'crisis' risks. The assessment serves to provide opportunities for learning and developing one's identity. Risks and challenges are two sides of the same medal. The assessment must be based on 1 Wishes and ambitions, 2 Strengths, 3 Values, 4 Support and 5 Risks and challenges. These aspects or parameters of recovery can be instrumental in evaluation and can be considered part of the shared decision-making process. The shared decision-making process is a rational process that is facilitated by certain interventions from the professional, but it is also a relational process in which the professional is present in the first place. What is open to discussion is the degree both repertoires can be combined, do justice to the vulnerability of a patient, prevent extreme harm and promote empowerment.

\section{Acknowledgement}

I would like to thank Josje Boere, community psychiatric nurse, for delivering the case.

\section{References}

1. Stickley T, Felton A (2006) Promoting recovery through therapeutic risk taking. Mental Health Practice 9(8): 26-30.

2. Kelly J, Wellman N, Sin J (2009) HEART-the hounslow early active recovery team: implementing an inclusive strength-based model of care for people with early psychosis. J Psychiatr Ment Health Nurs 16(6): 569577.

3. Robertson JP, Collinson C (2011) Positive risk taking: whose risk is it? An exploration in community outreach teams in adult mental health and learning disability services. Health, Risk \& Society 13(2): 147-164.

4. Bird V, Leamy M, Tew J, Le Boutillier C, Williams J, et al. (2014) Fit for purpose? Validation of a conceptual framework for personal recovery with current mental health consumers. Aust N Z J Psychiatry 48(7): 644653.

5. Heller NR (2014) Risk, hope and recovery: converging paradigms for mental health approaches with suicidal clients. The British Journal of Social Work 45(6): 1788-1803.

6. Tickle A, Brown D, Hayward M (2014) Can we risk recovery? A grounded theory of clinical psychologists perceptions of risk and recovery-oriented mental health services. Psychol Psychother 87(1): 96-110. 
7. De Jong M, Kamperman A, Oorschot M, Priebe S, Bramer W, et al. (2016) Interventions to Reduce Compulsory Psychiatric Admissions: A Systematic Review and Meta-analysis. JAMA Psychiatry 73(7): 657-664.

8. Higgins A, Doyle L, Downes C, Morrisey J, Costello P, et al. (2015) There is more to risk and safety planning than dramatic risks: Mental health nurses risk assessment and safety-management practice. Int J Ment Health Nur 25(2):159-170.

9. Rapp CA, Goscha RJ (2012) The strengths model. A recovery-oriented approach to mental health services. Oxford University Press, New York, USA.

10. Sitvast J (2018) Self-efficacy and social learning in mental health care. Journal of Psychiatry and Psychology Research 1(1): 15-18.
11. Hamkins S (2014) The art of narrative psychiatry: Stories of art and meaning. Oxford University Press: USA.

12. Felton A, Stickley T (2018) Rethinking risk: A narrative approach. Journal of Mental Health Training, Education and Practice 13(1): 54-62.

13. Woltmann EM, Whitley R (2010) Shared decision making in public mental health care: perspectives from consumers living with severe mental illness. Psychiatr Rehabil J 34 (1): 29-36.

14. Van Heijst A (2011) Professional loving care. An ethical view of the health care Sector. Peeters, Belgium.

15. Baart A (2004) Een theorie van de presentie. Lemma (third reprint), Utrecht, Netherlands.

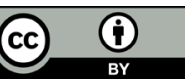

Creative Commons Attribution 4.0

International License

For possible submissions Click Here
Submit Article

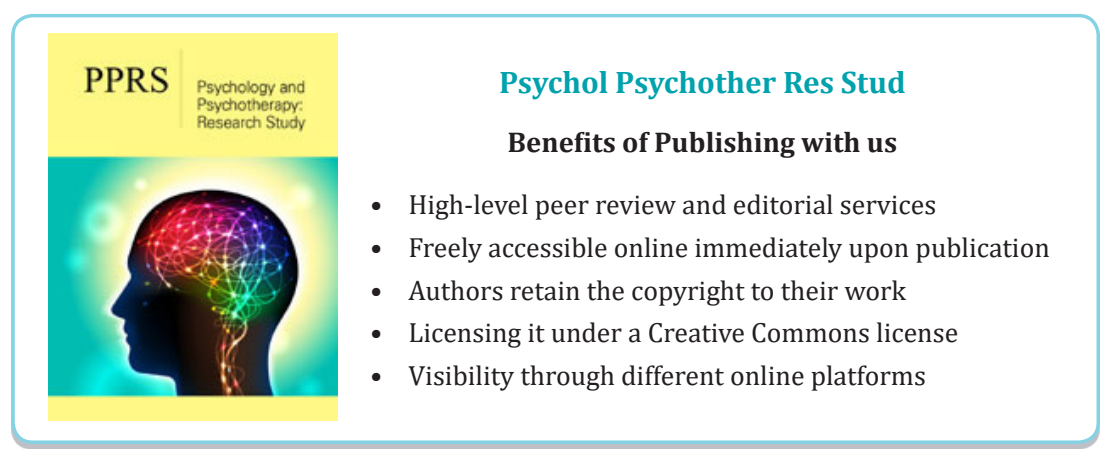

